\title{
Issues of Persuasion in Academic Law Abstracts
}

\author{
Ruth Breeze \\ University of Navarra \\ rbreeze@unav.es
}

\begin{abstract}
Across the academic world, abstracts may often serve a primary promotional function. However, it has also long been accepted that each academic field has its own perception of exactly what it means to be interesting and authoritative. Although abstracts in many disciplines have been extensively researched, so far those from the academic area of law have received little attention. This paper applies techniques of qualitative and quantitative analysis to 200 abstracts from four academic law journals (two European, two US based), and finds that their structure and language reflect specifically legal discourses of persuasion. Areas of commonality between the abstracts from European and US journals are discussed, while differences are analysed in terms of the underlying legal cultures.
\end{abstract}

\section{Introduction}

Much recent interest has focused on persuasive aspects of text types that have classically been regarded as chiefly informative or argumentative. One area that has been explored in some depth is that of academic writing. Researchers such as Hyland (1999, 2000, 2005), Afros and Schryer (2009) and Lindeberg (2004) have revealed how academic writers in the natural sciences, social sciences and humanities use a range of linguistic and rhetorical resources to persuade readers of the importance of their own work and, occasionally, downplay that of others. The features studied include indicators of overt authorial presence in the text, such as personal pronouns or self-citation (Harwood, 2005), lexical choices indicative of stance, including boosters, hedges or attitude markers (Hyland, 1999, 2000, 2005), the nature of centrality claims (Samraj, 2002), differential verb choice for the author's and other writers' actions (Breeze, 2008), and devices intended to engage the reader, such as direct address, 
appeals to shared knowledge, directives or questions (Hyland, 2005).

Among studies of academic writing, several papers have focused on the language of abstracts in particular (Anderson and Maclean, 1997; Kaplan et al., 1994; Martin, 2003; Swales and Feak, 2004). In the academic world, abstracts may often serve a primary promotional function, that of "selling" the paper in question to a conference or to a journal. In some circumstances, the impact made by the abstract may even determine whether the paper in question is finally written or not. According to Swales and Feak (2003:39), abstracts across a wide range of academic disciplines need to project "interestingness" and "a convincing and authoritative image" in order to persuade readers of their relevance. However, it has also long been accepted that each academic field has its own perception of exactly what it means to be interesting and authoritative (Berkenkotter and Huckin, 1995). Although abstracts in areas such as biomedicine or applied linguistics have been extensively researched (Santos, 1996; Huckin, 2001; Martín, 2003), so far those from the academic area of law have received little attention. Thus although many specific characteristics of lawyers' use of language have been the object of analysis (Bhatia 1983, 1993, 2004; Trosborg, 1996), the work of academic legal experts has not been subjected to in-depth scrutiny, and the language of abstracts in this field has not been thoroughly researched. The present study aims to offer some insights into law abstracts, and show how their persuasive features relate to, and contrast with, those found in other disciplines.

All research into persuasive language is faced at the outset with the complexity of defining exactly what falls into this category and what should be excluded. In some sense, even though the abstract is often superficially regarded as informative, a "neutral summary" of a text which "adds no new information, simply summarises" (Purdue Online Writing Lab), in reality its function is, at the very least, to draw attention to the importance of the paper, and perhaps also to ensure that it is accepted for a conference or a journal. Against this background, it might be claimed that the entire abstract has a persuasive function: not only particular aspects such as lexical choice or pronoun use, but also the text structure which foregrounds the main points of the paper, the strength and clarity of the claims made, and so on. However, to say that the text is entirely persuasive is also unhelpful, since such an assertion implies that without persuasion there would be no text, which is manifestly not the case. Although there is a sense in which the entire structure of the academic paper is a rhetorical construct that inserts inchoate, ongoing research activities into a positivist framework of reason (Knorr-Cetina, 1981), there is still a palpable difference between pure information (numbers, tables, the retelling of facts) and the organising, evaluating, relationship-building networks of language that are spun around this information. Under a robust definition of persuasion, then, all the elements which are not strictly necessary for the purposes of summarising the main information may at least be scrutinised for possible persuasive overtones.

Taking the opposite tack, viewing the situation entirely from the perspective of an interest in persuasive language per se, abstracts differ substantially from many other types of argumentative and promotional text, in that they are tightly bound by rigid disciplinary conventions and constrained by the actual contents of the paper that they summarise. In terms of persuasion, the abstract thus embodies a special type of compromise between the ostensible purpose to inform, and the inherent intention to draw positive attention to one's work. This 
paper will therefore take an inclusive view of what might constitute persuasive language in the case of academic law abstracts, starting from basic textual organization, and moving down to sentence-level features, which will be analysed by section. The issue of authorial presence and agency, which is present transversally throughout the moves, will be handled separately.

\section{Sample}

The sample of texts on which the present study is based consists of 50 abstracts from the 20062008 issues of each of four journals concerned with the academic study of Law. Two of the journals (American Law and Economics Review, henceforth ALER, published by Oxford University Press, and Journal of Legal Studies, JLS, published by the University of Chicago) focus mainly on the USA, and have a majority of US-based authors, while the other two (European Business Law Review, EBLR, published by Wolters Kluwer, and Journal of Corporate Law Studies, JCLS, published by Hart Publishing) centre principally on European issues, with mainly European-based authors, even though all four journals also include articles from and about other areas of the world. Regarding length, the instructions for authors published on the webpages of JLS and JCLS indicate that authors should submit 150-word abstracts with their contributions, while in the case of ALER the required length is 100 words. The guidelines for authors published by EBLR include no reference to an abstract, but the journal includes abstracts of 90-100 words for each article. In the case of EBLR, the abstracts may not have been written by the authors, but could have been added by the publisher at some stage prior to publication. This factor is taken into account in the course of the analysis.

\section{Macrostructure}

The first stage of analysis was to examine the macrostructure of each of the abstracts in the sample, using a framework developed from Swales's description of possible rhetorical moves (Swales, 1990; Swales and Feak, 2003; Samraj, 2005). The term "issue" is used, instead of the more conventional "purpose", because a problem or question that constituted the legal issue at stake figured in all the abstracts. This was then generally followed by an extremely brief statement which encapsulated both purpose and method. The other frequent moves were findings and discussion of findings. The example cited below contains all the moves, and can be regarded as typical of many of the abstracts in three of the journals (ALER, JLS, JCLS).

The holdout problem is commonly cited as the justification foreminent domain, but the nature of the problem is not well understood. This article models the holdout problem in a bargaining framework, where a developer seeks to acquire several parcels of land for a large-scale development. We show that in the absence of eminent domain, holdouts are a significant threat, resulting in costlydelay. However, if the developer has the power to use eminentdomain to acquire the land from holdouts, all sellers will bargain, thus avoiding delay. An offsetting cost is that owners may negotiateprices below their true value, possibly resulting in excessivetransfer of land to the developer. (ALER) 
However, in EBLR, the typical macrostructure consisted of fewer moves, as in the following example:

The article analyzes whether the World Trade Organisation (WTO) is legally capable of enforcing human rights in China through trade sanctions. It states that WTO does not have enough mechanisms to enforce human rights but it is up to the individual members to invoke it. According to the author, the problems on human rights is not solely the responsibility of WTO but also of international human rights laws and bodies like the International Labour Organisation (ILO). (EBLR)

An overview of the moves that were present in these sets of abstracts is displayed in Table 1.

\begin{tabular}{|l|l|l|l|l|l|}
\hline Journal & Introduction & Issue & Method & Findings & Discussion \\
\hline ALER & $26 / 50$ & $50 / 50$ & $38 / 50$ & $48 / 50$ & $39 / 50$ \\
\hline JLS & $27 / 50$ & $50 / 50$ & $37 / 50$ & $44 / 50$ & $35 / 50$ \\
\hline EBLR & $0 / 50$ & $50 / 50$ & $49 / 50$ & $44 / 50$ & $35 / 50$ \\
\hline JCLS & $26 / 50$ & $50 / 50$ & $45 / 50$ & $36 / 50$ & $45 / 50$ \\
\hline
\end{tabular}

Table 1. Moves present in abstracts.

As can be seen from Table 1, the introduction is the move which is least likely to occur in the present sample, being present in around half of the abstracts in ALER, JLS and JCLS, and completely absent from EBLR. The issue statement is evidently an obligatory move, which is explained by the fact that it encapsulates the research question that has prompted the article to be written. The method is usually mentioned cursorily, often in statements beginning "we analysed" or "this paper examines". Findings occupy a large proportion of the text in some cases, and are reported summarily in others. Most abstracts also included comments on the findings, which amounted to brief discussions.

The macrostructure of the texts thus differed somewhat from abstracts in other areas, reflecting the priorities of legal academic culture, which is doubtless shaped by practices and discourses in other legal domains. The features of the different sections will be discussed in greater depth below. Here, it should simply be noted that the prominence of the issue, which in many cases is foregrounded and acts as the principal "hook" to attract the reader, appears to be peculiar to legal academia, appealing to a discourse community in which the "issue" is the crucial focus of any discussion (Calleros, 2003). The abstract structure is thus configured by disciplinary discourses and values, persuading by ordering and framing the subject matter in a way that is easily recognisable for members of that community of practice.

\section{Introductory move}

Since the introduction is not universal, it is interesting to enquire as to what its function might be, and investigate the openings used in abstracts without an introduction as such.

In fields where structured abstracts are the norm, and in science generally, abstracts 
generally begin with an introductory statement that provides background, followed by aims, methods, results and conclusion sections (Nakayama, 2005). In disciplines where research paradigms are more open to variation, the abstract generally has an introductory section which may include a detailed justification of the particular piece of research, before moving into a brief account of the research itself(method) and its outcomes (results and conclusion) (Swales and Feak, 2003).

In both science and humanities abstracts, this introductory move is accorded considerable importance, to such an extent that it may even be the longest and most complex move (Martín, 2003), and may be a vehicle for explicit justification of the study in terms of real world issues (Samraj, 2005). However, the group of law abstracts under consideration in the present study was found not to obey this principle. As Table 2 shows, introductions were not an obligatory feature, and in one journal they were non-existent.

\begin{tabular}{|l|l|l|l|l|l|l|}
\hline Journal & $\begin{array}{l}\text { Introductory } \\
\text { move before } \\
\text { main issue is } \\
\text { stated }\end{array}$ & $\begin{array}{l}\text { Declarative } \\
\text { opening } \\
\text { (we/this paper } \\
\text { examines) }\end{array}$ & $\begin{array}{l}\text { Emphasis on } \\
\text { importance of } \\
\text { field }\end{array}$ & $\begin{array}{l}\text { Mention of } \\
\text { previous } \\
\text { work }\end{array}$ & $\begin{array}{l}\text { Mention } \\
\text { of } \\
\text { research } \\
\text { gap }\end{array}$ & $\begin{array}{l}\text { Statement } \\
\text { of issue or } \\
\text { problem }\end{array}$ \\
\hline ALER & $26 / 50$ & $20 / 50$ & $4 / 50$ & $13 / 50$ & $9 / 50$ & $50 / 50$ \\
\hline JLS & $27 / 50$ & $18 / 50$ & $15 / 50$ & $7 / 50$ & $5 / 50$ & $50 / 50$ \\
\hline EBLR & $0 / 50$ & $50 / 50$ & $0 / 50$ & $1 / 50$ & $0 / 50$ & $50 / 50$ \\
\hline JCLS & $26 / 50$ & $22 / 50$ & $4 / 50$ & $9 / 50$ & $6 / 50$ & $50 / 50$ \\
\hline
\end{tabular}

Table 2. Opening moves.

Around half the abstracts from 3 of the 4 journals had an introductory move preceding the declaration of purpose. Few of the writers used the three moves postulated by Swales for the research paper introduction (establishing a territory, establishing a niche, occupying a niche) (Swales, 1990), which some writers have postulated as being encapsulated in abbreviated form in the abstract (Samraj, 2005). However, some of the abstracts in this sample included allusions to the importance of the territory, some mentioned previous work in the field, and some mentioned a research gap, usually after a brief allusion to the area of research:

Empirical studies of corporate governance address potential endogeneity problems but fail to place endogeneity in the context of a model and ignore the possibility of disparate treatment effects across companies. This paper tackles these defects. ALER

Despite the long-standing insider trading debate, there is little empirical research on insider trading laws, especially in a comparative context. The article attempts to fill that gap. I find (...) ALER

However, in most cases, these introductory moves consisted of one short sentence to situate the reader in a particular area, as in the example below:

According to conventional wisdom, state-provided contract enforcement is critical to an expansive, growing trade. This paper estimates (...) ALER 
In many other abstracts, the introductory move was absent, the opening being achieved through a simple declaration of intent, as in the following examples:

This article analyses country-specific principles in the electronic securities holding systems in Germany and England. JCLS

This paper discusses mathematical modeling of the value of particular items of evidence. (JLS)

However, even within the reduced space allotted to them, where introductions were present they were frequently found to contain persuasive elements that went beyond the simple relaying of information. The persuasive language used in academic texts typically takes the form of boosters and hedges (generally referring to the epistemic value of propositions) and attitude markers (conveying the writer's affective stance to propositions) (see Hyland, 2005: 177). Using this framework, persuasive elements identified in the introductory section were quantified. Table 3 shows the number for each journal.

\begin{tabular}{|l|l|l|l|l|l|}
\hline Journal & Hedges & Boosters & $\begin{array}{l}\text { Positive } \\
\text { attitude }\end{array}$ & $\begin{array}{l}\text { Negative } \\
\text { attitude }\end{array}$ & $\begin{array}{l}\text { Negative } \\
\text { about gap }\end{array}$ \\
\hline ALER & 3 & 4 & 8 & 4 & 8 \\
\hline JLS & 5 & 7 & 5 & 9 & 13 \\
\hline EBLR & - & - & - & - & - \\
\hline JCLS & 7 & 2 & 23 & 8 & 7 \\
\hline
\end{tabular}

Table 3. Presence of hedges, boosters and attitude markers in the introductory move.

Hedges were found in some introductory sentences, examples being: may, might, could, seeming and seemingly. Boosters, that is, intensifiers, adjectives, etc., that are clearly epistemic in character, were also encountered, as might be expected in a discipline that is famed for its argumentative character. However, attitude markers, e.g. words or phrases indicating the writer's affective attitude to propositions, also proved surprisingly frequent. Most of those encountered had the function of conveying the importance, scope or difficulty of the area or problem being introduced, but there were also others that would seem to have less to do with the discourse of the law, such as: attractive, vital, spectacular, well-advanced, beneficial, staunch and popular, on the positive side; severe, antagonistic, limited, patchy, regrettable, battle, obstacle, pressure, on the negative side; and defect, conflicting, riddled with inconsistencies and uncertainties, heavily contested, puzzle and doubt to emphasise the knowledge gap. Attitude markers were particularly frequent in JCLS, which had 38 attitude markers across the 26 introductory moves available for analysis. In JLS, negative attitude markers were more frequent than their positive counterparts, and a large proportion of the attitude markers were used to stress the importance of the information gap. In ALER, most of the attitude markers were either positive or centred on the gap.

Differences aside, these data show an attempt on the part of many authors to persuade readers of the significance of their work. They accomplish this by drawing attention to the 
background to their research, either by signalling its importance and usefulness, by lamenting its severity or difficulty, or by proclaiming the urgent need for studies to fill a particular knowledge gap.

Another aspect of persuasion is the way in which a particular piece of research is positioned with regard to its potential targets. Two possible strategies have been identified: a paper may be strategically framed as a solution to or commentary on something that is extremely important in real terms (for people's lives, in the economy, in politics), or it can be focused as a challenging academic problem for scholars to solve (Samraj, 2005). Thus some authors prefer to proclaim their work as relevant to an important phenomenon in the world, while others choose to situate their work firmly within an academic context. In those abstracts which had introductory moves, the type of centrality claim was identified, following Samraj's (2005) distinction between claims to real-world importance and assertions concerning active research activity in the area. An emblematic example of the real-world centrality claim in the opening sentence from an abstract in the present sample would be "The events of 2000-2002 have considerably changed corporate life", whereas the centrality claim based on active academic research interest is epitomised by "Prior research has produced conflicting evidence of racial profiling during traffic stops". In the former case, the information is framed as an arresting problem affecting the business world, while in the latter, the foregrounding of "prior research" functions to establish that the issue of "racial profiling" is a focus of academic interest.

\begin{tabular}{|l|l|l|}
\hline Journal & Real-world relevance & Active research interest \\
\hline ALER & 14 & 12 \\
\hline JLS & 15 & 9 \\
\hline EBLR & - & - \\
\hline JCLS & 21 & 6 \\
\hline
\end{tabular}

Table 4. Centrality claims in introductory move.

Table 4 shows that real-world importance was invoked more frequently in all the journals where introductory moves were found. This trend was particularly marked in JCLS, where 21 abstracts began with a reference to a pressing problem or dilemma in the real world, and only 6 chose to foreground the research interest.

To summarise, the introductory statement, though not obligatory, is deployed by many of these authors as a means to persuade their readers of the interest and usefulness of their work. To achieve this end, the authors draw on a repertoire of resources, including arresting or emotive lexis, particularly to emphasise importance, usefulness or difficulty, or to decry the yawing research gap that their work will fill. The nature of the appeal varies, although in some journals, the relevance of the matter in real life definitely prevails over its perceived academic interest. 


\section{Issue statements}

As mentioned above, what does appear to be an essential component of abstracts in academic legal studies is the inclusion of what might be termed the "issue": a question, dilemma or problem that forms the focal point of the paper. In around half the abstracts in this sample, and all those from EBLR, the opening statement encapsulated the issue in a declarative opening. In other cases, the issue was stated after a brief introductory move.

In other areas of legal writing, the "issue" is regarded as being of paramount importance. Defined as "a material question of fact or law that arises from the claims, defenses and arguments of the parties" (Calleros, 2002: 102), an issue statement is often placed at the beginning of documents such as legal memoranda, letters of advice and case briefs (Calleros, 2002: 102, 193 and 496). It also constitutes the crucial second move that follows the explanation of background in legal case studies (Lung, 2008). In both continental and common law traditions, lawyers are trained to identify the legal issue or question in any state of affairs, but in Anglo-American common law cultures, which favour inductive procedures based on the analysis of leading cases, this skill is accorded enormous importance. The issue thus constitutes the central feature of legal analysis and method, and much of the training of attorneys focuses on learning how to identify issues within specific cases. In the present sample, the blunt manner in which the issue statement is presented, often without a preamble of any kind, may be supposed to insert the text into the ongoing discourses of law where issues are accorded a significant status. It thus operates much in the way that a newspaper headline might, by referring readers directly to a topic which has already been deemed important by social consensus.

Since the issue statement appeared to be an obligatory move, it was investigated in greater depth, according to whether it was expressed as a direct question, an indirect question, or embedded in some nominalised construction, as illustrated by the three examples below:

Direct question: When is it socially desirable to allocate discretionary authority to the adjudicators, and if so, to what extent? ALER

Indirect question: This article analyzes whether the goals of the 2002 European Commission (EC) Directives on telecommunications up to the 2008 ongoing revision have been reached. EBLR

Embedded issue: This article discusses the roles of the International Monetary Fund (IMF) and the World Bank in financial sector reform and compliance. EBLR

\begin{tabular}{|l|l|l|l|}
\hline Journal & Direct question & Indirect question & Embedded issue \\
\hline ALER & $2 / 50$ & $6 / 50$ & $43 / 50$ \\
\hline JLS & $4 / 50$ & $5 / 50$ & $39 / 50$ \\
\hline EBLR & $0 / 50$ & $2 / 50$ & $48 / 50$ \\
\hline JCLS & $8 / 50$ & $1 / 50$ & $47 / 50$ \\
\hline
\end{tabular}

Table 5. Types of issue statement used. 
Table 5 illustrates the frequency of these three approaches to the issue statement in the four journals.

In all four journals, embedded issue statements were the most frequent kind, often relying on nominalisation to encapsulate the main question: "this article discusses the regulation of medicinal products", or "This article presents a discussion on arbitration in Denmark and analyzes the options which parties have under the new Danish Arbitration Act (AA)". The trend towards nominalisation in written English, and particularly in specialised registers, has been well documented (Halliday and Martin, 1993; Gotti, 2008). Nominalisation permits greater concision, and makes it possible to introduce concepts or verbal actions in thematic position, thus facilitating the flow of complex information (Gotti, 2008). Moreover, as Halliday pointed out (1990), nominalisation tends to confer a sense of objectivity, presenting processes or actions as a state of affairs, something to be taken for granted. Within the area of law, Bhatia has noted that nominalisation "helps a legal draftsman to make his provisions more compact and yet precise and all-inclusive" (Bhatia, 1994: 142). This holds for legislation and for the drafting of legal documents, but may also affect other areas of legal writing in which the need to sound objective is combined with high information density. On this basis, it may be surmised that in the abstract, nominalisation serves a dual function: to permit complex ideas to be conveyed concisely; and to present processes or actions as objective "issues". In using this style, legal academics are both following the norms of legal writing, and using a convention common to many technical and scientific disciplines. The persuasive function of this phenomenon should not be ignored, however. By objectifying actions through nominalisation, the writer is already according them the status of an "issue", a pressing question or matter which requires attention. In the reduced space of the abstract, these nominalisations may even serve the function of "key words" (not provided separately in these journals), which can be identified swiftly on a superficial reading. They thus advertise the main issue covered by the article in terms that their readers will quickly assimilate.

The role of direct questions in this context is also interesting. In the present sample, direct questions were found in all but one of the journals, and JCLS was found to have a relatively high frequency ( 8 questions in 50 abstracts). Direct questions are rare in academic writing, and quite unusual in abstracts (Samraj, 2005), and their use is generally marked, suggesting that the writer wishes to project a stronger individual voice (Hyland, 1999). According to Hyland (2005: 185), although direct questions are "the strategy of dialogic involvement par excellence", in academic contexts they tend to be applied rhetorically, as a persuasive stratagem. Their use in these legal abstracts would appear to diverge from this norm, however, since they serve chiefly to frame the issue or research question in a clear, straightforward way. In fact, the frequency of direct questions has been identified as a feature of written legal language, perhaps as a result of transfer from the other domains of legal practice. Lawyers are generally trained to "spot the issue", and the issue in a given case may well be expressed most succinctly as a question. Other authors have noted a certain trend towards using direct questions more frequently in academic writing about law than in other disciplines (Gotti, 2008b). Although this is not conclusive, the relatively high frequency of direct questions may be best explained as reflecting the typical patterns of legal discourse, rather than as an attempt to achieve a direct interpersonal style. 
A final point about the issue statement is that its formulation, whether as a question or as a nominalised issue, is generally characterised by neutral lexis, and may be merged with references to method: "this article studies the effects of accounting fraud on the product market", or "we investigate how bankruptcy use relates to countries' creditor rights and judicial efficiency". This terseness, combined with the absence of an introductory move in many cases, makes many of these abstracts appear extremely dry and unappealing at first sight. One must assume that for legal scholars, the main interest of the abstract lies in the issue, which constitutes a "hot topic" in a given field (Swales and Feak, 2003). The fact that the issue is expressed succinctly, even elliptically, may even aid readers who are glancing through the journal, functioning somewhat in the way of key words, a convention which these legal journals have not yet adopted.

\section{Findings and discussion}

The findings and discussion moves in these abstracts are often inseparably intertwined, with description and comment blended together in the same sentences. As in the case of the introductory move, there is a tendency to modulate or highlight aspects of the findings and discussion with boosters, hedges or attitude markers.

\begin{tabular}{|l|l|l|l|l|}
\hline Journal & Hedges & Boosters & Positive attitude & Negative attitude \\
\hline ALER & 35 & 10 & 26 & 5 \\
\hline JLS & 47 & 10 & 46 & 12 \\
\hline EBLR & 11 & 1 & 7 & 14 \\
\hline JCLS & 41 & 7 & 65 & 21 \\
\hline
\end{tabular}

Table 6. Hedges, boosters and attitude markers in findings and discussion moves.

Table 6 shows that hedges and attitude markers were frequent in the findings and discussion moves of all the sets except that from EBLR, which again proved to run counter to the general trend. In ALER, JLS and JCLS, there was a strong tendency for authors to hedge their findings and conclusions, while using positive attitude markers to indicate the importance or interest of their results and arguments. Often, positive attitude markers are combined with hedges to create an impression of cautious judicial recommendation, as in the examples "could usefully be taken into account" or "the results suggest that sentence length (...) is the relevant performance metric". The epistemological value of the author's assertions is thus tempered by hedging, but this is offset by the use of positive attitude markers that may be intended to influence readers positively in favour of the author's arguments and conclusions. A subtle balancing act is thus being performed, setting legal caution against forensic oratory to encourage positive reactions to the author's work.

None of these arguments holds for EBLR, however, where the paucity of attitudinal language was slightly offset by the relatively large number of negative attitude markers. This could be attributed to the fact that the writers of these abstracts (who, as has been suggested 
above, may not have been the authors) often end on a negative note by mentioning a problem or conflict arising out of the foregoing discussion.

\section{Authorial presence and agency}

The issue of authorial presence in the text has classically been analysed by investigating the use of personal pronouns and possessives, particularly we, our, I and my (Hyland, 2001). Such items are easily quantifiable, and have formed the basis of various studies of academic writing at different levels of competence (Hyland, 1999, 2005). According to Hyland (2005: 181), use of the first person is usually a conscious choice, the underlying intention being "to adopt a particular stance and disciplinary-situated authorial identity". In general, they are found to be infrequent in scientific writing, and more common in the humanities and social sciences (Hyland, 1999). Table 7 shows the number of personal pronouns/possessives in each set of 50 abstracts in the present study.

\begin{tabular}{|l|l|l|}
\hline Journal & we/our & I \\
\hline ALER & $44 / 50$ & $7 / 50$ \\
\hline JLS & $52 / 50$ & $12 / 50$ \\
\hline EBLR & $0 / 50$ & $0 / 50$ \\
\hline JCLS & $5 / 50$ & $0 / 50$ \\
\hline
\end{tabular}

Table 7. Personal pronouns/possessives in abstracts.

It can be seen that the two US-focused journals had a much higher incidence of authorial selfmention than the European journals. The discoursal self projected by the writers in ALER and JLS was much stronger, perhaps reflecting a greater desire to identify themselves with particular arguments or stress the originality of their claims. On the other hand, the abstracts from EBLR were entirely devoid of first person pronouns, and the abstracts from JCLS only contained five instances of we. It has been argued that the tendency to "write the subject out" in the sciences subtly conveys an empiricist ideology suggesting that research outcomes are objective and wholly immune to researcher bias. In the case of EBLR and JCLS, the greater degree of impersonality conveyed in the text may be symptomatic of a European academic legal culture in which overt authorial presence is felt to be unscholarly. To take an extreme position, the absence of personal voice in these texts may be a metaphorical reflection of the lawyer's role in a European civil law context, in which the law is taken to be a well-thought-out system located in objective codes, and the lawyer or academic lawyer's role is to analyse and reproduce it, rather than take a stance towards it or attempt to develop it further. Conversely, the loud authorial voice in ALER and JLS might reflect common law adversarial systems of justice, in which the individual attorney develops an argument to beat down his/her opponent (and the individual judge may one day leave his or her mark on the law itself in the form of a binding precedent).

On the other hand, it should be stated that the special case of EBLR may also be explained 
by the possibility that these abstracts were not written by the authors themselves. In such a case, it would hardly be likely for the person who composed the abstract to use personal pronouns. Yet it is curious that authors publishing in JCLS also opt for a low-profile approach, which adds some weight to the arguments set out above.

To delve further into the nature of authorial presence and agency in the texts, a further analysis was carried out, this time focusing on the nature of the verbs used to denote the author's actions, expressed either directly, with we or $I$, or indirectly, by circumlocutions such as "this paper explains" or "it is explained in this paper". Issues such as this aspect of lexical choice have been analysed less frequently than pronoun use, perhaps because of the intrinsic difficulty of distinguishing agency using corpus methodology. None the less, previous studies have suggested that the choice of verb may be one of the ways in which authors seek to persuade their readers as to the importance, relevance, reliability or originality of their work (Swales, 1990; Moore, 2002; Breeze, 2008). This type of verb use includes what Halliday (1994) classed as "metaphenomenal discourse", in which the phenomena described are not stated directly, but projected by some participant in the research/writing process (e.g. using a verb of thinking or saying). However, our analysis also covers actions, since many of the verbs collocating with we or this paper referred to research activities rather than thinking or reporting, and the use of these verbs of action also added to the degree of agency embedded in the text. Since a large number of verbs were found in both functions, only the most salient are shown in Table 8 (those occurring more than four times in a particular set of abstracts).

\begin{tabular}{|l|l|lr|}
\hline Journal & $\begin{array}{l}\text { Verbs used with we/I to describe } \\
\text { author's actions }(>4\end{array}$ & $\begin{array}{l}\text { Verbs used impersonally to describe } \\
\text { author's actions ( }>4\end{array}$ \\
\hline ALER & $\begin{array}{l}\text { find (18) } \\
\text { argue (5) } \\
\text { show (5) }\end{array}$ & $\begin{array}{l}\text { suggest (11) } \\
\text { examine (5) }\end{array}$ & \\
\hline JLS & $\begin{array}{l}\text { show (11) } \\
\text { find (9) } \\
\text { examine (5) }\end{array}$ & $\begin{array}{l}\text { examine (9) } \\
\text { explain (5) } \\
\text { contribute (5) }\end{array}$ & $\begin{array}{r}\text { examine (6) } \\
\text { focus (5) } \\
\text { EBLR }\end{array}$ \\
& & $\begin{array}{l}\text { discuss (25) } \\
\text { present (12) } \\
\text { analyse (12) } \\
\text { note (7) } \\
\text { state (7) }\end{array}$ & offer (5) \\
\hline JCLS & & $\begin{array}{l}\text { examine (21) } \\
\text { argue (12) } \\
\text { consider (12) } \\
\text { suggest (7) }\end{array}$ & $\begin{array}{r}\text { assess (6) } \\
\text { evaluate (5) } \\
\text { focus (5) } \\
\text { analyse (5) }\end{array}$ \\
\hline
\end{tabular}

Table 8. Verbs used to indicate what authors did, said or thought.

Table 8 displays the most salient verbs used to report what the author says, thinks or does (personal agency) or what the paper says, thinks or does (impersonal reporting). The only verbs collocating with we and I are find, show, argue and examine, each of which is interesting in conveying a particular aspect of the way academic lawyers construct themselves within the 
text. Find is used frequently by the writers in ALER to give the results of their investigations. One might surmise that their use of find rather than one of the many synonyms for obtaining results or discovering information may be influenced by the typically legal use of find and finding by lawyers to mean "determining a factual question vital to or contributing to a decision in a case" (Alcaraz, 2002; Law.Com, 2009). It would hardly be surprising should terminology of this kind be transferred from one domain (the courtroom) to another (legal academia), within the same common law culture. Show, though less specifically legal, also belongs within the area of demonstrate or prove, and its use again reflects an academic culture that pursues evidence to verify claims within a positivist paradigm.

A similar process of transfer, this time not only pertinent to the common law world but part of the shared legal culture, might be responsible for the use of the term examine for any activity involving enquiry or analysis. This non-metadiscoursal verb reflected the author's agency in conducting careful research, again with forensic overtones ("to examine evidence", "to cross-examine a witness", etc.). In addition to examine, the verbs analyse, assess and evaluate were also used, all of which draw attention to the author's research activity as intellectual performance within a positivist, even quasi-scientific paradigm (Moore, 2002; Bruce, 2009). Arguably, the framing of the author's work as action helps to situate the researcher as an active member of the discourse community who is forging ahead to obtain new, objective data and submit these to objective scrutiny.

Some other frequent verbs for authorial activity were discursive in nature (explain, discuss, suggest, argue). Since argument and explanation form a large part of the work of lawyers and scholars alike, it is unsurprising that they should be prominent in the way they construct their research activities. It was noticeable that only EBLR, in which the abstracts may not have been composed by the authors themselves, was found to have a high frequency of neutral verbs conveying a low degree of agency, such as present, note or offer, which contributed to the pedestrian and rather repetitive character of these abstracts. The abstracts from EBLR also had a high incidence of discuss and state, two non-committal verbs of "saying", which also tend to produce a sense of diffidence and lack of commitment to the content matter.

In general, it can be said that the verb choice in abstracts from ALER, JLS and JCLS tends to follow the pattern of persuasion that has been found to be typical of academic writing in "hard" disciplines, in that it appeals to rationality, relying on might classically be termed logos (Lindberg, 2004; Afros and Schryer, 2009: 59), or discipline specific arguments. Thus there is a strong emphasis on the intellectual performance of research (examine, assess, evaluate, focus, show), coupled with declarations of discursive performance (argue, explain). However, this performativity is firmly anchored within the positivist tradition, leaning towards the sciences on the one hand, and the courtroom on the other.

\section{Conclusion}

All disciplinary cultures tend to generate specialised genres, and it is becoming increasingly obvious that even seemingly related genres like the academic abstract may vary greatly from 
one discipline to another in the ways that they seek the acceptance and approval of the peer group. This exploration of the academic law abstract has brought to light various features that make it particularly interesting to discourse analysts and applied linguists.

In general, the academic law abstract is the product of a particular disciplinary culture, the culture of academic law, which has developed its own discourses and generic patterns over the centuries. The foregoing analysis has shown how the abstract reflects a way of thinking and persuading that is discipline-specific. The structures of thought underlying these abstracts, with their heavy emphasis on the issue and their subtle projection of an investigative, analytical and sometimes adversarial persona, would seem to be indicative of a mature academic paradigm (Kuhn, 1970) in which certain values are assumed to be shared, even across major cultural divides.

The discourses of university lawyers, be they from common or civil law traditions, can be said to be woven between the abstruse, archaic, technical language of the law, on the one hand, and the performances of adversarial or inquisitorial justice and positivist inquiry on the other. As part of their professional and academic training, lawyers learn to identify and foreground the issue that is at stake in any argument. In their abstracts, they thus place the issue in the central position, sometimes fronting it with a claim to real-world relevance or academic interest, sometimes nominalising it to create the sense of a readily recognisable phenomenon, sometimes framing it courtroom-style as a direct question. The issue is the principal hook and axis of the legal abstract, the lynchpin to the whole text, and as such, it receives no particular emphasis or boosting.

Aside from the issue statement, the classic abstract moves of introduction, method, results or findings, and discussion, which would all appear to be optional, are often carefully couched with hedges and attitude markers. In the introductory move, positive attitude markers signal the importance of the topic, while negative ones emphasise the seriousness of the knowledge gap. In the findings and discussion moves, a delicate balance is maintained between hedging the truth-value of the author's arguments and strengthening them subjectively by the use of evaluative adjectives, adverbs or nouns. With a combination of legal and scholarly caution, these authors seem unwilling to commit themselves to a strong conclusion in the abstract, yet choose subtly to sway the balance towards their own viewpoint by careful lexical choice.

As far as the authors' presence and agency are concerned, the two US-focused journals had a high incidence of personal pronoun use, and verb choice to indicate the authors' role centred on the performances of positive academic enquiry: examining, finding, showing, arguing and explaining. In JCLS, authors' personal presence was much more muted, but the verb choice was broader, with a greater emphasis on ratiocination and judgement, perhaps reflecting a larger proportion of Europeans among the authors: examine, consider, argue, assess, analyse. In EBLR, where European authors also predominated, the verb choice was non-committal, as shown by the preference for verbs such as: discuss, offer, present, state and note. However, as noted above, it is doubtful that the authors themselves wrote these paragraphs, and so the neutral style of the abstract may have been determined by the fact that their writer had a low degree of commitment to the text. In general, the degree of authorial presence and type of agency projected through the text would seem to vary according to the cultural background of the authors and, perhaps, editors. The mainly European authors in 
JCLS and EBLR preferred a more discreet presence, while the American authors were more vocal, more individually assertive, willing to assume the argumentative voice of the lawyer to convince their readers.

This brief examination of academic law abstract has thus shed further light on the rhetorical mechanisms of persuasion, showing how a short and apparently neutral genre can reflect a particular disciplinary culture which in turn reverberates within the creative tension that exists between the professional and academic domains.

\section{References}

Alcaraz Varó, Enrique (2002): El inglés jurídico (5th ed.). Barcelona: Ariel.

Berkenkotter, Carol and Thomas Huckin (1995): Genre Knowledge in Disciplinary Communication. Hillsdale NJ: Lawrence Erlbaum.

Bhatia, Vijay (1983): "Simplification versus easification: the case of legal texts". Applied Linguistics 4(1): $42-54$.

. (1993): Analysing Genres. Language Use in Professional Settings. London: Longman.

. (1994): “Cognitive structuring in legislative provisions”. In J. Gibbons, ed., Language and the Law. London: Longman, 136-155.

. (2004): Worlds of Written Discourse. London: Continuum.

Breeze, Ruth (2008): "They say, we do: writers' strategic positioning in the discourses of political communication research". InterLAE Conference, Jaca, 11-13 December 2008.

Bruce, Ian (2009): "Results sections in sociology and organic chemistry articles: A genre analysis". English for Specific Purposes 28(2): 105-124.

Calleros, Charles R. (2002): Legal Method and Writing. New York: Aspen.

Gotti, Maurizio (2008): Investigating Specialized Discourse. Bern: Peter Lang.

. (2008b): "Identity traits in written academic discourse across languages and cultures". InterLAE Conference, Jaca, 11-13 December 2008.

Halliday, M.A.K. (1990): "The construction of knowledge and value in the grammar of scientific discourse with reference to Charles Darwin's The Origin of Species". In C. De Stasio, M. Gotti and R. Bonadei, eds., La rappresentazione verbale e iconica: valori estetici efunzionali. Milan: Guerini. . (1994): An Introduction to Functional Grammar (2nd ed.). London: Edward Arnold.

Halliday, M.A.K. and J.R. Martin(1993): Writing Science: Literacy and Discursive Power. London: Falmer Press.

Huckin, Thomas (2001): “Abstracting from abstracts". In M. Hewings, ed., Academic writing in context: Implications and applications. Birmingham: University of Birmingham Press, 93-103.

Hyland, Ken (2000): Disciplinary Discourses: Social Interactions in Academic Writing. London: Longman.

. (2001): "Bringing in the reader: addressee features in academic writing". Written Communication 18(4): 549-574.

. (2005): "Stance and engagement. A model of interaction in academic discourse". Discourse Studies 7(2): 173-192

Kaplan, Robert, Selena Cantor, Cynthia Hagstrom, Lia Kamhi-Stein, Yumiko Shiotani and Cheryl Zimmerman (1994): "On abstract writing". Text 14(3): 401-426.

Knorr-Cetina, Karin (1981): The Manufacture of Knowledge: An Essay on the Constructivist and 
Contextual Nature of Science. Oxford: Pergamon Press.

Kuhn, Thomas (1970): The Structure of Scientific Revolutions (2nd ed.). Chicago: University of Chicago Press.

Law.Com Dictionary. 2009. Available at: http://dictionary.law.com on 27 March 2009

Lung, Jane (2008): “Discursive hierarchical patterning in Law and Management cases". English for Specific Purposes 27 (4): 424-441.

Martín Martín, Pedro (2003): “A genre analysis of English and Spanish research paper abstracts in experimental social sciences". English for Specific Purposes 22(1): 25-43.

Moore, Tim (2002): "Knowledge and agency: a study of 'metaphenomenal discourse' in textbooks from three disciplines". English for Specific Purposes 21 (4): 347-366.

Nakayama, Takeo, Nobuko Hirai, Shigeaki Yamazaki and Mariko Naito (2005): "Adoption of structured abstracts by general medical journals and format for a structured abstract". Journal of the Medical Library Association 93(2): 237-242.

Purdue Online Writing Lab. How to write a report abstract. Available at: http://owl.english.purdue.edu/owl/ (21 March 2009)

Samraj, Betty (2002): "Introductions in reseach articles. Variations across disciplines". English for Specific Purposes 21(1): 1-17. . (2005): "An exploration of a genre set. Research article abstracts and introductions in two disciplines". English for Specific Purposes 24(2): 141-156.

Santos, M.B. (1996): "The textual organization of research paper abstracts in applied linguistics". Text 16(4): 481-499.

Swales, John (1990): Genre analysis: English in academic and research settings. Cambridge: Cambridge University Press.

Swales, John and Christine Feak (2003): English in today's research world. A writing guide. Ann Arbor: University of Michigan.

Trosborg, Anna (1996): Rhetorical Strategies in Legal Language. Discourse Analysis of Statutes and Contracts. Tübingen: Gunter Narr. 